\title{
A phase I and pharmacokinetic study of indisulam in combination with carboplatin
}

\author{
C Dittrich ${ }^{*, 1}$, AS Zandvliet ${ }^{2}$, M Gneist', ADR Huitema ${ }^{2}$, AAJ King ${ }^{3}$ and J Wanders ${ }^{3}$ \\ 'Ludwig Boltzmann-Institute for Applied Cancer Research (LBI-ACR VIEnna) and ACR-ITR VIEnna, Third Medical Department - Centre for Oncology and \\ Haematology, Kaiser Franz Josef-Spital, A-I 100 Vienna, Austria; ${ }^{2}$ Department of Pharmacy and Pharmacology, The Netherlands Cancer Institute/ \\ Slotervaart Hospital, NL-1066 EC Amsterdam, The Netherlands; ${ }^{3}$ Eisai Ltd., 3 Shortlands, London, W6 8EE, UK
}

Indisulam (E7070) is an anticancer agent that is currently being evaluated in phase II clinical studies. A significant reduction in glutathione synthetase and glutathione reductase transcripts by indisulam provided a molecular basis for its combination with platinum agents. Indisulam demonstrated high anti-tumour activity in various preclinical cancer models. The objectives of this study were (I) to determine the recommended dose of indisulam in combination with carboplatin in patients with solid tumours and (2) to evaluate the pharmacokinetics of the combination. Patients with solid tumours were treated with indisulam in combination with carboplatin. Indisulam (350,500, or $600 \mathrm{mg} \mathrm{m}^{-2}$ ) was given as a I-hour intravenous infusion on day I and carboplatin (5 or

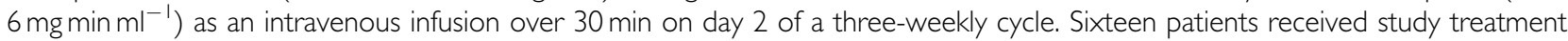
and were eligible. Thrombocytopenia was the major dose limiting toxicity followed by neutropenia. Both drugs contributed to the myelosuppressive effect of the combination. Indisulam $500 \mathrm{mg} \mathrm{m}^{-2}$ in combination with carboplatin $6 \mathrm{mg} \mathrm{min} \mathrm{ml}^{-1}$ was identified not to cause dose limiting toxicity, but a delay of re-treatment by I week was required regularly to allow recovery from myelosuppression. The recommended dose and schedule for an envisaged phase II study in patients with non-small cell lung cancer is indisulam $500 \mathrm{mg} \mathrm{m}^{-2}$ in combination with carboplatin $6 \mathrm{mg} \mathrm{min} \mathrm{ml}^{-1}$ repeated four-weekly. Patients who do not experience severe thrombocytopenia at cycle I will be permitted to receive an escalated dose of indisulam of $600 \mathrm{mg} \mathrm{m}^{-2}$ from cycle 2 onwards. British Journal of Cancer (2007) 96, 559-566. doi: I0.1038/sj.bjc.6603606 www.bjcancer.com

Published online 6 February 2007

(c) 2007 Cancer Research UK

Keywords: indisulam; carboplatin; phase l; pharmacokinetics

Indisulam (E7070) is a chloro-indolyl sulphonamide anticancer agent that induces dose- and time-dependent G1 cell-cycle arrest in addition to delay in G1/S transition and S-phase progression (Fukuoka et al, 2001). Significant downregulation of particular sets and subsets of genes involved in cell-cycle control and energy metabolism was observed. Inhibition of carbonic anhydrase isoform IX (CAIX), which was initially supposed to be the main mechanism of action does not appear to be able to explain the whole aspects of indisulam anti-tumour activity (Owa et al, 2004). Very recently, indisulam was found to promote the production of reactive oxygen species before cellular apoptosis. Several dehydrogenase enzymes have been identified so far as indisulam binding proteins, suggesting that the cellular redox control system connected with mitochondrial functions might be a potential primary target of indisulam (Oda et al, 2003).

A single agent phase II study revealed evidence of only weak activity and an acceptable toxicity profile in patients with non-

\footnotetext{
*Correspondence: Dr C Dittrich, Professor of Medicine, Ludwig Boltzmann-Institute for Applied Cancer Research, Kaiser Franz JosefSpital, Kundratstrasse 3, A-I 100 Vienna, Austria;

E-mail: christian.dittrich@wienkav.at

Received 26 September 2006; revised 3 January 2007; accepted 7 January 2007; published online 6 February 2007
}

small cell lung cancer (NSCLC), who had received prior treatment with platinum-based chemotherapy (Talbot et al, 2002).

Preclinical studies indicated that the combination of indisulam with platinum was synergistic in both cell line isobologram analysis and in NSCLC xenograft models, possibly by reducing intracellular glutathione (Ozawa et al, 2004). Sequencing carboplatin 1 day after the application of indisulam is based on experiments with human tumour xenografts in nude mice in which a significant downregulation of glutathione synthetase mRNA was detected by quantitative real-time polymerase chain reaction (RT-PCR) $24 \mathrm{~h}$ after administration of indisulam. As this enzyme is critical to maintain intracellular levels of glutathione that inactivates platinum species, this sequence guarantees noncompromised anti-tumour activity of carboplatin given on day 2 after indisulam (Owa T, Eisai Co Ltd, Japan; personal communication).

The currently presented dose escalation study was performed to identify a safe dose of indisulam in combination with carboplatin that can be tested in patients with NSCLC or other platinumsensitive malignancies. For more than a decade, platinum-based chemotherapy represents the standard of care for NSCLC (Bunn et al, 1994). In a recently published prospectively randomised phase III study which compared four different platinum containing doublets, no significant difference with regard to response and survival was detected between three cisplatin- and one carboplatincontaining regimen (Schiller et al, 2002). The carboplatin-containing 
treatment arm was associated with even less toxicity overall, particularly with respect to febrile neutropenia and nausea. In a recent survey, a carboplatin-containing combination was found to be the most widely favoured option for first-line chemotherapy in all stages of NSCLC among US medical oncologists (Choy et al, 2000). This relates to ease of administration on an out-patient basis, manageable toxicity profiles compared with other platinumcontaining regimens and promising phase II trial results (Langer et al, 1995; Muggia et al, 1995; Belani et al, 1996; Johnson et al, 1996).

The objectives of this study were (1) to determine the recommended dose of indisulam in combination with carboplatin in patients with solid tumours and (2) to evaluate the pharmacokinetics of the combination.

\section{PATIENTS AND METHODS}

\section{Eligibility}

Patients, $\geqslant 18$ years old, with a histologically/cytologically confirmed solid tumour refractory to standard therapy or for whom no established therapy exists were eligible. Their Karnofsky performance status must have been $\geqslant 70 \%$; they had to present with adequate haematological, renal and hepatic function as defined by absolute neutrophil count of $\geqslant 1.5 \times 10^{9} 1^{-1}$; platelet count of $\geqslant 100 \times 10^{9} 1^{-1}$; haemoglobin level of $\geqslant 10 \mathrm{~g} \mathrm{dl}^{-1}$; serum bilirubin $\leqslant 1.5$ times the upper limit of normal, alanine aminotransferase (ALT) and aspartate aminotransferase (AST) $\leqslant 2.5$ times the upper limit of normal ( $\leqslant 5$ times the upper limit of normal in the presence of hepatic metastases); and serum creatinine $\leqslant 1.5$ times the upper limit of normal or a creatinine clearance $\geqslant 60 \mathrm{ml} \mathrm{min}^{-1}$ (by Cockcroft-Gault formula).

Each of the following conditions represented an exclusion criterion: more than two previous lines of chemotherapy; incomplete recovery from surgery or radiation therapy; previous chemotherapy within 4 weeks of study entry; uncontrolled infections; significant cardiac impairment; and history of sensitivity to sulphonamides or platinum agents.

Written informed consent fulfilling the requirements of the ethics committee was required to be obtained from all patients before entry into the study.

\section{Treatment plan and study design}

Indisulam dosing was based on body surface area and carboplatin doses were calculated with the Calvert formula to produce an area under the concentration-time curve (AUC) of 5 or $6 \mathrm{mg} \mathrm{min} \mathrm{ml}^{-1}$ (Calvert et al, 1989; van Kesteren et al, 2002). The starting dose of the combination was indisulam $350 \mathrm{mg} \mathrm{m}^{-2}$ administered as a 1-h intravenous infusion on day 1 and carboplatin $6 \mathrm{mg} \mathrm{min} \mathrm{ml}^{-1}$ as a 30 -min infusion on day 2, repeated every 3 weeks. The dose escalation scheme is summarised in Table 1 . The dose of indisulam was to be escalated in subsequent cohorts consisting of three patients to 500,600 and $700 \mathrm{mg} \mathrm{m}^{-2}$ according to the toxicity

Table I Summary of planned dose escalation scheme

\begin{tabular}{|c|c|c|}
\hline Dose level & $\begin{array}{c}\text { Indisulam }\left(\mathrm{mg} \mathrm{m}^{-2}\right) \\
\text { day I }\end{array}$ & $\begin{array}{c}\text { Carboplatin }\left(\mathrm{mg} \mathrm{min} \mathrm{ml}^{-1}\right) \\
\text { day } 2\end{array}$ \\
\hline One & 350 & 6 \\
\hline Two & 500 & 6 \\
\hline Three & 600 & 6 \\
\hline Four & 700 & 6 \\
\hline$x$ & Maximum tolerated dose & 5 \\
\hline$x+1$ & Maximum tolerated dose + one & 5 \\
\hline
\end{tabular}

observed at prior dose levels. If one of the first three patients experienced dose-limiting toxicity (DLT) during cycle 1, the number of patients treated at this dose level was expanded to six. Provided that none of the additional three patients experienced a DLT during cycle 1 , dose escalation was continued. When a dose of indisulam was reached at which $\geqslant 33 \%$ of the patients in a cohort of six experienced DLT during their first cycle of the combination, the dose of carboplatin was reduced from 6 to $5 \mathrm{mg} \mathrm{min} \mathrm{ml}^{-1}$. If the maximum tolerated dose (MTD) of indisulam was well tolerated in combination with carboplatin $5 \mathrm{mg} \mathrm{min}^{-1}$, the indisulam dose was finally escalated to the next dose level.

\section{Patient evaluation and follow-up}

Patients attended the clinic for a screening visit up to 14 days before treatment start to assess eligibility. Physical examination was performed as well as Karnofsky performance status was assessed at screening and vital signs as well as laboratory assessment (urinalysis, haematology, clinical chemistry) were carried out weekly till the final visit 30 days after the last intake of study drug. Patients were followed up for survival.

Tumour assessments according to RECIST criteria were carried out at screening and then every 6 weeks. ECGs were taken at screening and before and after study drug administration at day 1 only. Adverse events and concomitant medications were recorded on an ongoing basis from the date of consent until the final visit.

Dose limiting toxicities were assessed in the first cycle of treatment and were defined according to version 2.0 of the NCI common toxicity criteria (CTC): (i) ₹ grade 3 non-haematological toxicity directly related to study treatment (other than untreated nausea and vomiting), (ii) grade 4 thrombocytopenia, (iii) grade 4 neutropenia for $\geqslant 7$ days and (iv) $\geqslant$ grade 3 febrile neutropenia.

Dose reductions for unacceptable toxicity up to a maximum of two per patient were permitted. Once, the dose had been reduced it was not increased at a later date. A delay of up to 2 weeks was permitted in between cycles.

\section{Pharmacokinetic study}

Full pharmacokinetic sampling of indisulam and carboplatin were performed during the first cycle of treatment. Blood samples $(4 \mathrm{ml})$ for indisulam analysis were obtained at 15 time points for up to 8 days after the first administration: pre-infusion, $30 \mathrm{~min}$ after the start of infusion, at the end of the infusion, at 10 and $30 \mathrm{~min}$ and at $1,2,4,6,8,24,48,72,96$ and $168 \mathrm{~h}$ after the end of the infusion. In addition, indisulam samples were taken before infusion and at the end of infusion during cycle 2 . Immediately after collection, the samples were centrifuged at room temperature for $10 \mathrm{~min}$ at 1500 g. Plasma was collected and immediately stored at $-20^{\circ} \mathrm{C}$ until analysis. The concentrations of indisulam in plasma were measured using high-performance liquid chromatography coupled to an electrospray ionization tandem mass spectrometer (LC/ESIMS/MS) as described previously (Beumer et al, 2004).

Blood samples $(5 \mathrm{ml})$ for carboplatin analysis were obtained at eight time points on day 1: before administration, at the end of infusion and at $1,2,4,6,8$ and $23 \mathrm{~h}$ after the end of infusion. Immediately after collection, the samples were centrifuged at $4{ }^{\circ} \mathrm{C}$ for $5 \mathrm{~min}$ at $1500 \mathrm{~g}$. Immediately after centrifugation for plasma separation, aliquots of the collected plasma were transferred to Amicon ultrafiltration devices with an YMT-14 membrane $(30 \mathrm{kDa}$ MW cutoff; Millipore Corporation, Bedford, MA, USA). Ultrafiltrate was prepared by centrifuging this device at $1500 \mathrm{~g}$ for $15 \mathrm{~min}$ at room temperature. The plasma ultrafiltrates were stored frozen at $-20^{\circ} \mathrm{C}$ until analysis of free platinum; the remaining plasma was stored frozen at $-20^{\circ} \mathrm{C}$ until analysis of total platinum. Plasma concentrations were measured by graphite-furnace atomic-absorption spectrometry (van Warmerdam et al, 1995). 


\section{Population pharmacokinetic analysis}

The pharmacokinetic profile of indisulam monotherapy was described previously by a population pharmacokinetic model using nonlinear mixed effects modelling (Zandvliet et al, 2006). The model consisted of multiple compartments corresponding to plasma, erythrocytes, interstitial fluid and tissue. Indisulam was eliminated via two pathways: a linear and a saturable pathway. The pharmacokinetic parameters describing the model for indisulam monotherapy were applied to calculate model predicted indisulam concentrations, which were compared to the observed plasma concentration of indisulam. If the model adequately predicted the observed concentrations, it could be concluded that the pharmacokinetic profile of indisulam was not highly influenced by combination therapy with carboplatin. The population pharmacokinetic analyses were performed using NONMEM software (version V, level 1.1) (GloboMax LLC, Hanover, MD, USA) after logarithmic transformation of the data (Beal et al, 1988).

The pharmacokinetic results of ultrafiltrable carboplatin were also evaluated by compartmental analysis using NONMEM software. The data were fitted to a linear two-compartment model (Huitema et al, 2000; Shen et al, 2002; Ekhart et al, 2006). Pharmacokinetic parameters were compared to previously published reports (Huitema et al, 2000; Shen et al, 2002; Ekhart et al, 2006). Differences may indicate a pharmacokinetic interaction between carboplatin and indisulam. Furthermore, the observed carboplatin clearance of the studied patients, as determined by the population pharmacokinetic analysis, was compared to the predicted carboplatin clearance, as calculated using the Calvert formula (Eq. 1) (Calvert et al, 1989). Calvert et al (1989) demonstrated that the total plasma clearance of carboplatin was linearly related to the glomerular filtration rate (GFR) and that the non-renal clearance was $25 \mathrm{ml} \mathrm{min}^{-1}$.

$$
\mathrm{CL}_{\text {carboplatin }}=\mathrm{GFR}+25
$$

The estimated creatinine clearance $\left(\mathrm{CL}_{\mathrm{cr}}\right)$ was considered as a measure of GFR and was calculated from measured serum creatinine $\left(\mathrm{CR}, \mu \mathrm{moll}^{-1}\right)$, age (years), gender $(0=$ male, $1=$ female) and weight (kg) using the Cockcroft and Gault's (1976) formula:

$$
\mathrm{CL}_{\mathrm{cr}}=\frac{(140-\text { age })(\text { weight })(1-0.15 \times \text { gender })}{72(\mathrm{CR}) 0.0113}
$$

Serum creatinine levels were measured by enzymatic methods. If the observed carboplatin clearance corresponded well to the predictions from the Calvert formula, it could be concluded that the clearance of carboplatin was not affected by indisulam.

\section{Pharmacokinetic-pharmacodynamic analysis}

Relationships between drug exposure and platelet counts were explored to find potential relationships between pharmacokinetics and haematological toxicity. The area under the plasma concentration $v s$ time-curve (AUC) of indisulam and carboplatin ultrafiltrate were used as measures of drug exposure in this analysis. The relationship between the nadir platelet count and the exposure to indisulam $\left(\mathrm{AUC}_{\mathrm{ind}}\right)$ and carboplatin $\left(\mathrm{AUC}_{\mathrm{carb}}\right)$ at cycle 1 was described by a modified Hill equation:

$$
\begin{aligned}
& \frac{\text { nadir platelet count }}{\text { baseline platelet count }}= \\
& \left(1-\frac{\mathrm{AUC}_{\text {ind }}^{\gamma 1}}{\left(\mathrm{AUC}_{\text {ind }}^{\gamma 1}+\mathrm{AUC} 50_{\text {ind }}^{\gamma 1}\right)}\right)\left(1-\frac{\mathrm{AUC}_{\text {carb }}^{\gamma 2}}{\left(\mathrm{AUC}_{\text {carb }}^{\gamma 2}+\mathrm{AUC}^{\gamma / 2} 0_{\text {carb }}\right)}\right)
\end{aligned}
$$

\section{RESULTS}

\section{Dose escalation and safety assessment}

Seventeen patients registered for the study; 16 patients received treatment with indisulam and carboplatin. Characteristics of eligible patients are listed in Table 2.

Patients were treated at four different dose levels (Table 3). Four patients were treated with $350 \mathrm{mg} \mathrm{m}^{-2}$ indisulam and $6 \mathrm{mg} \mathrm{min} \mathrm{ml}^{-1}$ carboplatin. One patient died from progressive

\begin{tabular}{|c|c|}
\hline \multicolumn{2}{|l|}{ Gender } \\
\hline Male & $5(31 \%)$ \\
\hline Female & II (69\%) \\
\hline \multicolumn{2}{|l|}{ Age (years) } \\
\hline Median & 63 \\
\hline Range & $|9-8|$ \\
\hline \multicolumn{2}{|l|}{ Height $(\mathrm{cm})$} \\
\hline Median & 164 \\
\hline Range & $153-185$ \\
\hline \multicolumn{2}{|l|}{ Race } \\
\hline Caucasian & $16(100 \%)$ \\
\hline \multicolumn{2}{|l|}{ Time since diagnosis (months) } \\
\hline Median & 30 \\
\hline Range & $2-335$ \\
\hline \multicolumn{2}{|l|}{ Tumour type } \\
\hline Sarcoma & 3 \\
\hline Renal cell & 2 \\
\hline Lung & 2 \\
\hline Colorectal & 2 \\
\hline Ovarian & 2 \\
\hline Pancreas & 2 \\
\hline Adenocarcinoma & I \\
\hline Melanoma & I \\
\hline Gastric & । \\
\hline \multicolumn{2}{|l|}{ Previous therapy } \\
\hline Surgery & $16(100 \%)$ \\
\hline Radiotherapy & $5(31 \%)$ \\
\hline Chemotherapy, I course & $5(31 \%)$ \\
\hline Chemotherapy, 2 courses & $4(25 \%)$ \\
\hline Chemotherapy, 3 courses & $1(6 \%)$ \\
\hline Chemotherapy, 4 courses & $2(13 \%)$ \\
\hline Experimental therapy & $4(25 \%)$ \\
\hline
\end{tabular}
disease before completing 1 cycle of study treatment and was therefore replaced in the cohort. Three patients were treated at the

\begin{tabular}{|c|c|c|c|c|}
\hline $\begin{array}{l}\text { Indisulam } \\
\left(\mathrm{mg} \mathrm{m}^{-2}\right)\end{array}$ & $\begin{array}{l}\text { Carboplatin } \\
\left(\mathrm{mg} \mathrm{min} \mathrm{ml}^{-1}\right)\end{array}$ & $\begin{array}{c}\text { Number of } \\
\text { patients treated }\end{array}$ & DLTs & $\begin{array}{l}\text { Patients with } \\
\text { dose reductions } \\
\text { at cycle } 2\end{array}$ \\
\hline 350 & 6 & $4^{\mathrm{a}}$ & 0 & 0 \\
\hline 500 & 6 & 3 & 0 & 0 \\
\hline 600 & 6 & 4 & $3(75 \%)$ & 2 \\
\hline 600 & 5 & $5^{b}$ & $2(50 \%)^{c}$ & 0 \\
\hline
\end{tabular}
second dose level. At the initial two dose levels, no DLTs were

Table 2 Patient characteristics

Table 3 Number of patients, DLTs, dose reductions per dose level

DLTs, dose limiting toxicities. ${ }^{a}$ One patient was not assessable for DLT, because he

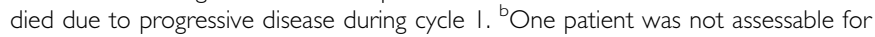
$\mathrm{DLT}$, because she died due to progressive disease during cycle I ${ }^{\mathrm{T}}$ Two DLTs out of four assessable patients. 
observed and the combination was well tolerated at cycle 1 . However, all patients who received more than one treatment cycle required a delay in the start of subsequent cycles to recover from haematological toxicity. Four patients were treated at dose level 3. At cycle 1, two patients had dose-limiting grade 4 thrombocytopenia and one patient had grade 3 thrombocytopenia with haemorrhage (this was not defined as a DLT, but was considered as one by the investigator as it yielded consecutive partial liver resection owing to the intra-hepatic bleeding). A fourth patient in this cohort experienced CTC grade 4 neutropenia at cycle 3 . The MTD of indisulam when administered in combination with carboplatin was consequently defined as $600 \mathrm{mg} \mathrm{m}^{-2}$. Consecutively, five patients were treated with $600 \mathrm{mg} \mathrm{m}^{-2}$ indisulam and $5 \mathrm{mg} \mathrm{min} \mathrm{ml}^{-1}$ carboplatin. Two patients experienced DLTs at cycle 1 at this dose.

Overall, indisulam $600 \mathrm{mg} \mathrm{m}^{-2}$ in combination with carboplatin was too toxic. Nonetheless, a dose of $500 \mathrm{mg} \mathrm{m}^{-2}$ indisulam and carboplatin $6 \mathrm{mg} \mathrm{min} \mathrm{ml}^{-1}$ was considered to be safe at cycle 1 .
A total of 53 cycles of the combination were delivered, with a median of 2 cycles and a range of $1-7$ cycles. Of 37 doses that were administered after the first treatment cycle, 30 (81\%) were delayed by 1 or 2 weeks owing to unresolved thrombocytopenia and/or neutropenia.

Sixteen patients were evaluated for toxicity. Table $4 \mathrm{a}$ represents a summary of treatment-related adverse events. Nearly all severe adverse events were haematological toxicities (thrombocytopenia, neutropenia and anaemia) occurring by day 15 of each cycle, and resolving after at least 7 days. Table $4 \mathrm{~b}$ shows the number of patients with haematological toxicity CTC grade 3 or 4 at cycle 1 and post cycle 1 . Thrombocytopenia was the major DLT at cycle 1. Furthermore, all patients who received more than one treatment cycle experienced thrombocytopenia as a result of the combination treatment with indisulam and carboplatin. Non-haematological side effects were minor and can be neglected.

Severe adverse events related to study treatment reported during the study were: grade 4 thrombocytopenia (2), grade 3 thrombo-

Table 4a Treatment-related adverse events observed during the study by worst grade according to the NCl-common toxicity criteria (CTC)

\begin{tabular}{|c|c|c|c|c|c|c|c|c|c|c|}
\hline \multirow{2}{*}{$\begin{array}{l}\text { Dose level }^{\mathrm{a}} \\
\text { Number of evaluable patients } \\
\text { CTC grade }\end{array}$} & \multicolumn{2}{|c|}{$\begin{array}{c}350 / 6 \\
4\end{array}$} & \multicolumn{2}{|c|}{$\begin{array}{c}500 / 6 \\
3\end{array}$} & \multicolumn{2}{|c|}{$\begin{array}{c}600 / 6 \\
4\end{array}$} & \multicolumn{2}{|c|}{$\begin{array}{c}600 / 5 \\
5\end{array}$} & \multicolumn{2}{|c|}{$\begin{array}{l}\text { All } \\
16\end{array}$} \\
\hline & $1-2$ & $3-4$ & $1-2$ & $3-4$ & $1-2$ & $3-4$ & $1-2$ & $3-4$ & $1-2$ & $3-4$ \\
\hline Thrombocytopenia & 0 & 3 & 0 & 2 & 1 & 2 & 0 & 4 & | (6\%) & || (69\%) \\
\hline Neutropenia & I & 2 & I & I & 0 & 3 & 0 & 4 & $2(12.5 \%)$ & $10(62.5 \%)$ \\
\hline Anaemia & 2 & I & I & I & 0 & 3 & I & 2 & $4(25 \%)$ & $7(44 \%)$ \\
\hline Nausea & 2 & 0 & 2 & 0 & 2 & 0 & 2 & 0 & $8(50 \%)$ & $0(0 \%)$ \\
\hline Vomiting & 3 & 0 & 0 & 0 & 2 & 0 & । & 0 & $6(37.5 \%)$ & $0(0 \%)$ \\
\hline Constipation & 2 & 0 & I & 0 & 3 & 0 & 0 & 0 & $6(37.5 \%)$ & $0(0 \%)$ \\
\hline Dysgeusia & 0 & 0 & 1 & 0 & I & 0 & 2 & 0 & $4(25 \%)$ & $0(0 \%)$ \\
\hline Anorexia & 1 & 0 & 1 & 0 & I & 0 & I & 0 & $4(25 \%)$ & $0(0 \%)$ \\
\hline Abdominal pain & 2 & 0 & 0 & 0 & 2 & 0 & 0 & 0 & $4(25 \%)$ & $0(0 \%)$ \\
\hline Dry mouth & I & 0 & 0 & 0 & । & 0 & 1 & 0 & $3(19 \%)$ & $0(0 \%)$ \\
\hline Peripheral oedema & 0 & 0 & । & 0 & 0 & 0 & 1 & 0 & $2(12.5 \%)$ & $0(0 \%)$ \\
\hline Dry skin & I & 0 & I & 0 & 0 & 0 & 0 & 0 & $2(12.5 \%)$ & $0(0 \%)$ \\
\hline
\end{tabular}

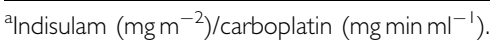

Table 4b Number of patients with any treatment-related haematological toxicity grade 3 or 4 according to the NCl-common toxicity criteria (CTC) at cycle I and post cycle

\begin{tabular}{|c|c|c|c|c|c|c|c|c|c|c|}
\hline \multirow{3}{*}{$\begin{array}{l}\text { Dose level }^{\mathrm{a}} \\
\text { Number of evaluable patients } \\
\text { CTC grade }\end{array}$} & \multirow{2}{*}{\multicolumn{2}{|c|}{$\begin{array}{c}350 / 6 \\
4\end{array}$}} & \multicolumn{2}{|c|}{$500 / 6$} & \multicolumn{2}{|c|}{$600 / 6$} & \multicolumn{2}{|c|}{$600 / 5$} & \multicolumn{2}{|c|}{ All } \\
\hline & & & & & & & & & & \\
\hline & 3 & 4 & 3 & 4 & 3 & 4 & 3 & 4 & 3 & 4 \\
\hline Platelets & 0 & 0 & I & 0 & 1 & 2 & 3 & 1 & $5(3 \mid \%)$ & $3(19 \%)$ \\
\hline Neutrophils & 0 & 0 & 0 & 0 & 1 & I & 0 & I & I (6\%) & $2(13 \%)$ \\
\hline Leucocytes & 0 & 0 & 0 & 0 & 1 & 0 & 1 & 1 & $2(13 \%)$ & I (6\%) \\
\hline Lymphocytes & 0 & 0 & 0 & 0 & 0 & 0 & I & 0 & I (6\%) & $0(0 \%)$ \\
\hline \multicolumn{11}{|l|}{ Post cycle I } \\
\hline Platelets & 3 & 0 & 2 & 1 & 1 & 2 & 4 & 1 & 10 (63\%) & $4(25 \%)$ \\
\hline Neutrophils & 2 & 0 & 2 & I & 3 & 2 & 2 & 4 & 9 (56\%) & 7 (44\%) \\
\hline Leucocytes & 2 & 0 & 1 & 0 & 1 & 0 & 4 & 2 & $8(50 \%)$ & $2(13 \%)$ \\
\hline Lymphocytes & I & 0 & 0 & 0 & 0 & 0 & 3 & 0 & $4(25 \%)$ & $0(0 \%)$ \\
\hline Haemoglobin & 2 & 0 & I & 0 & 2 & 0 & 2 & 0 & 7 (44\%) & $0(0 \%)$ \\
\hline
\end{tabular}

Indisulam $\left(\mathrm{mg} \mathrm{m}^{-2}\right)$ /carboplatin ( $\left.\mathrm{mg} \mathrm{min} \mathrm{ml}^{-1}\right)$. 
cytopenia with bleeding (1), grade 4 neutropenia (1), grade 4 anaemia (1) and grade 2 supra-ventricular tachycardia (1).

Three patients died on study (within 30 days of last study treatment) due to progressive disease. Six patients withdrew due to adverse events, four due to progressive disease according to RECIST criteria, three due to clinical progressive disease, one due to abnormal laboratory values (neutropenia grade 3 ) and one withdrew consent.

\section{Response}

Ten patients completed at least two cycles of study treatment and were evaluable for response. Eight patients showed stable disease and two patients had progressive disease.

\section{Population pharmacokinetic analysis}

Sixteen patients were evaluable for pharmacokinetics. Time profiles of indisulam plasma concentrations were adequately described by the population pharmacokinetic model. Observed indisulam plasma concentrations corresponded well to the modelbased predictions (Figure 1). The median exposures to indisulam expressed as the AUC were 47,94 and $116 \mathrm{mg} \mathrm{min} \mathrm{ml}^{-1}$ for dose levels 350,500 and $600 \mathrm{mg} \mathrm{m}^{-2}$ and AUCs ranged from 25 to $198 \mathrm{mg} \mathrm{min} \mathrm{ml}^{-1}$.

The two-compartmental model produced a good fit to the ultrafiltrable carboplatin concentrations. Estimated pharmacokinetic parameters are listed in Table 5. Carboplatin clearance was lower than in previous studies. Conversely, the intercompartmental clearance was relatively high. Other parameters corresponded well to published values. Figure 2 shows that the carboplatin clearance was overpredicted by the Calvert formula for all patients. This resulted in a carboplatin exposure that was higher than the target exposure. The median exposure was $6.1 \mathrm{mg} \mathrm{min} \mathrm{ml}^{-1}$ for target $5 \mathrm{mg} \mathrm{min} \mathrm{ml}^{-1}$ and $6.7 \mathrm{mg} \mathrm{min} \mathrm{ml}^{-1}$ for target $6 \mathrm{mg} \mathrm{min} \mathrm{ml}^{-1}$. Carboplatin AUC ranged from 5 to

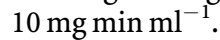

\section{Pharmacokinetic-pharmacodynamic analysis}

The severity of thrombocytopenia was expressed as the nadir platelet count and was related to the exposure to indisulam and carboplatin. Myelosuppression was assessed at the first treatment cycle. Fourteen patients were evaluable for this PK-PD analysis. Their nadir platelet count ranged from $4 \times 10^{9}$ to $154 \times 10^{9} 1^{-1}$ corresponding to a range of $1.2-45 \%$ of the baseline platelet count. The relative nadir platelet count, expressed as a percentage of the baseline platelet count, decreased with both indisulam AUC $(P=0.003)$ and carboplatin AUC $(P=0.004)$. The AUC of indisulam resulting in a $50 \%$ decrease in platelet count (AUC50 ind in Eq. 3) was estimated at $28.5 \mathrm{mg} \mathrm{min} \mathrm{ml}^{-1}$ (relative standard error (RSE) 21\%). The thrombocytopenic effect of carboplatin was half maximal at an AUC of $7.74 \mathrm{mg} \mathrm{min} \mathrm{ml}^{-1}$ (RSE 13\%) $\left(\right.$ AUC50 $0_{\text {carb }}$ in Eq. 3). The Hill factor $\gamma 1$ was not significantly different from $1 \quad(P=0.57)$. The myelosuppressive effect of carboplatin was best described by a sigmoidal $\mathrm{E}_{\max }$ model and $\gamma^{2}$ was estimated at 10.9 (RSE 70\%). The relationship between the relative nadir platelet count and the exposure to indisulam and carboplatin is depicted in Figure 3A and B. The model predicted nadir platelet counts were unbiased and corresponded reasonably well to the observed values (Figure 3C). The modified Hill equation adequately described the relative nadir platelet count after treatment with indisulam in combination with carboplatin.

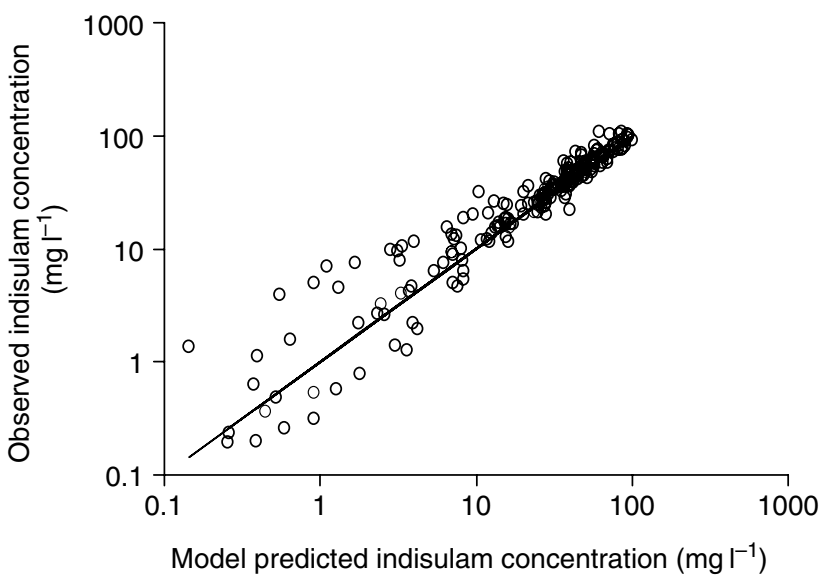

Figure I Observed vs model predicted plasma concentrations of indisulam. The scatter plot is symmetrically positioned around the line of identity, which indicates that the currently observed profiles are well described by the previously developed population pharmacokinetic model.

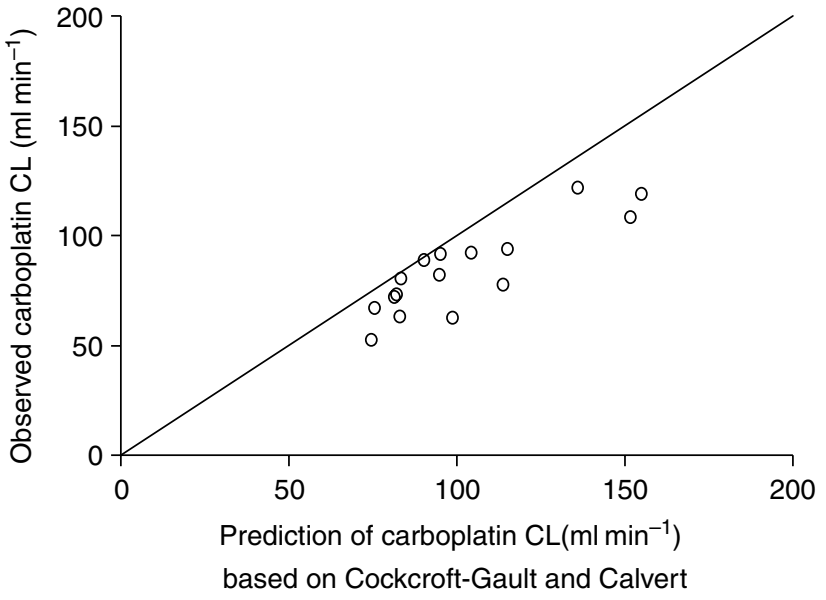

Figure 2 Observed carboplatin clearance $(\mathrm{CL})$ vs predicted carboplatin clearance based on Cockcroft and Gault (1976) and Calvert et al (1989).

Table 5 Population pharmacokinetic parameter estimates of carboplatin ultrafiltrate

\begin{tabular}{|c|c|c|c|c|c|}
\hline Pharmacokinetic parameter & Previous reports $^{a}$ & Current estimate & (\%SE) & IIV\% & (\%SE) \\
\hline
\end{tabular}

SE, standard error; IIV, interindividual variability. ${ }^{a}$ Huitema et al, (2000); Shen et al, (2002); Ekhart et al, (2006). 
A
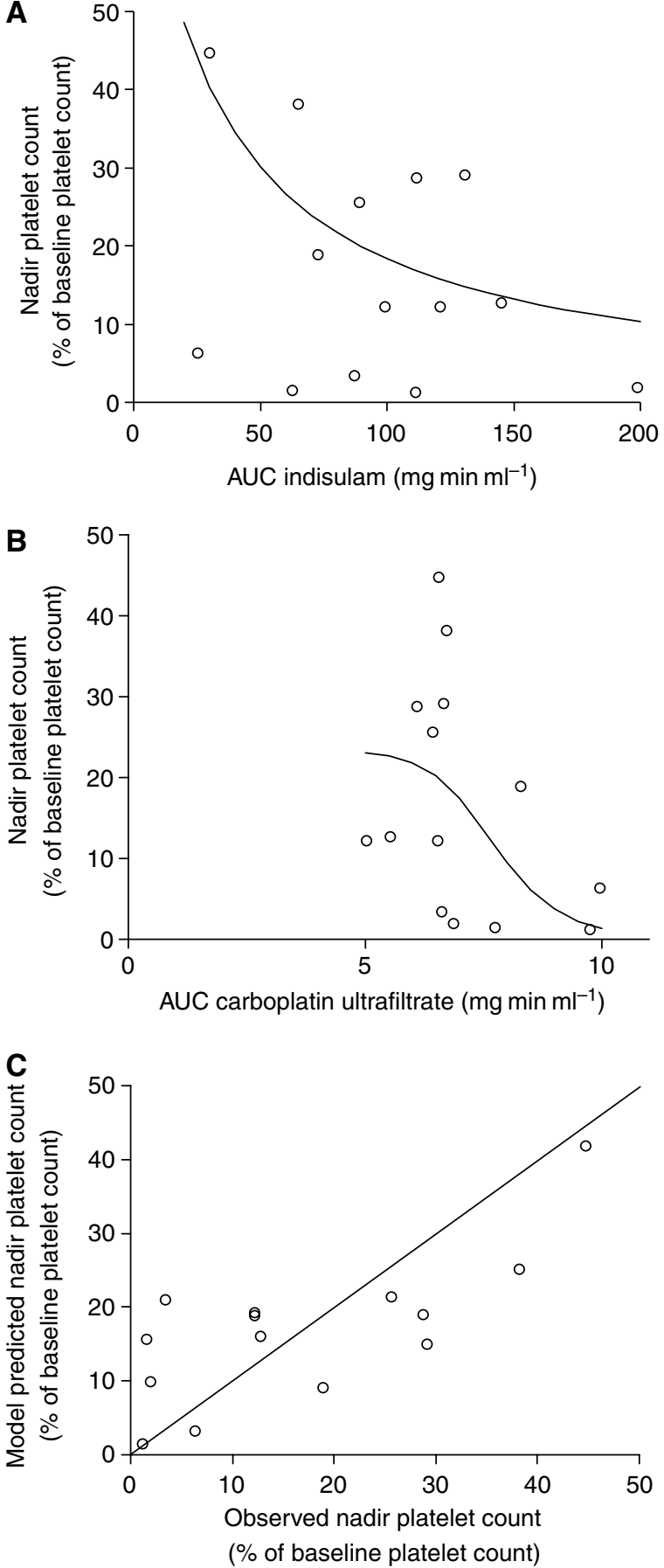

Figure 3 The relative nadir platelet count vs exposure to indisulam $(\mathbf{A})$ and exposure to carboplatin (B). The solid lines represent the model predicted nadir counts after median exposure to carboplatin (6.7 $\mathrm{mg} \mathrm{min} \mathrm{ml}^{-1}$ ) and varying exposure to indisulam (A) or after median exposure to indisulam $\left(94 \mathrm{mgminm}^{-1}\right.$ ) and varying exposure to carboplatin (B). A plot of model predicted values vs the corresponding observed values $(\mathbf{C})$ is symmetrically distributed around the line of unity, which demonstrates that the modified Hill equation resulted in unbiased predictions of the nadir platelet count. AUC, area under the plasma concentration vs time curve.

\section{DISCUSSION}

Both, the weak anti-tumour activity of indisulam as single agent at a dosage of $700 \mathrm{mg} \mathrm{m}^{-2}$ as intravenous infusion over $1 \mathrm{~h}$ every 3 weeks, demonstrated by tumour regressions of lesser degree than required for an objective response in about third of the patients treated and the low rate of toxicity with less than a quarter of all patients experiencing grade 3 or 4 haematological toxicity, which represented the main toxicity, did not only justify but merely prompted us to combine indisulam with a substance with known anti-tumour activity against NSCLC (Talbot et al, 2002). As a consequence, carboplatin was selected (Bunn et al, 1994; Langer et al, 1995; Muggia et al, 1995; Belani et al, 1996; Johnson et al, 1996; Choy et al, 2000; Schiller et al, 2002).

Haematological toxicity was dose limiting for indisulam in combination with carboplatin. Minimal non-haematological toxicity was observed after treatment with the combination.

A dose of $500 \mathrm{mg} \mathrm{m}^{-2}$ indisulam and $6 \mathrm{mg} \mathrm{min} \mathrm{ml}^{-1}$ carboplatin was well tolerated at cycle 1 . However, dose delays were common due to prolonged marrow recovery from the previous treatment. Therefore, a 3-weekly treatment cycle was not sustainable. Thus, for a future phase II study with indisulam and carboplatin in chemotherapy naïve patients with NSCLC, a 4-weekly schedule was proposed. In this phase II study, patients will be treated with the safe dose of $500 \mathrm{mg} \mathrm{m}^{-2}$ indisulam with $6 \mathrm{mg} \mathrm{min} \mathrm{ml}^{-1}$ carboplatin at cycle 1 . Patients with minor thrombocytopenia (less than grade 3 ) at cycle 1 may receive an escalated dose of indisulam of $600 \mathrm{mg} \mathrm{m}^{-2}$ at cycle 2, because previous studies have demonstrated a high correlation between the extent of prior chemotherapy and the incidence of haematological toxicity.

Myelosuppression was previously identified as the DLT for single agent therapy with both indisulam and carboplatin (Calvert et al, 1982; Raymond et al, 2002). Thrombocytopenia was identified as the major toxicity of the combination. The nadir platelet count decreased with increasing exposure to both indisulam and carboplatin. This phenomenon can be interpreted as the result of the addition of a similar behaviour of the two substances by increasing their dosages separately, but not primarily as the result of its pharmacodynamic interaction. Single agent high dose carboplatin, that is, $520-1000 \mathrm{mg} \mathrm{m}^{-2}$, covering the exposure of an AUC ranging from 5 to $10 \mathrm{mg} \mathrm{min} \mathrm{ml}^{-1}$, which was reached in our study, yielded severe and cumulative bone marrow suppression in ovarian cancer patients (Wiltshaw et al, 1987). Both, leucopenia and thrombocytopenia reached their nadirs at day 15; leucopenia $<1000$ leucocytes $\mu \mathrm{l}^{-1}$ lasted 4 days (range 1-11 days), thrombocytopenia $<100000$ platelets $\mu \mathrm{l}^{-1}$ lasted 12 days (range 4-40 days). Recommendations for target AUC for obtaining an acceptable degree of myelosuppression resulted in an AUC of 5-7 $\mathrm{mg} \mathrm{min} \mathrm{ml}^{-1}$ for carboplatin single agent therapy and in an AUC of 4-5 $\mathrm{mg} \mathrm{min} \mathrm{ml}^{-1}$, when the drug was to be used in combination with other myelosuppressive agents (Calvert et al, 1989). In a phase II study in which carboplatin was tested at an AUC of $7 \mathrm{mg} \mathrm{min} \mathrm{ml}^{-1}$ - corresponding well with the median exposure of $6.7 \mathrm{mg} \mathrm{min} \mathrm{ml}^{-1}$ for target AUC $6 \mathrm{mg} \mathrm{min} \mathrm{ml}^{-1}$ in our study - every 4 weeks in advanced breast cancer patients, leucopenia at the time of scheduled re-treatment was found to be of grade 3 in $6 \%$ of the patients, of grade 2 in $15 \%$ and of grade 1 in $22 \%$; the respective value for thrombocytopenia was grade 3 in $5 \%$ of the patients (O’Brien et al, 1993). Martin et al (1992), who tested a dosage of only $400 \mathrm{mg} \mathrm{m}^{-2}$, every 4 weeks, in metastatic breast cancer patients, observed only infrequent and mild leucopenia and thrombocytopenia on day 28 . Overall, leucopenia of only WHO grade $1-2$ was found in $47 \%$ of the patients or $18 \%$ of the courses and thrombocytopenia in $12 \%$ of the patients or $3 \%$ of the courses, respectively. A scarce trial in which carboplatin was tested at a 3-weekly period, as foreseen in our study, but at a dosage of only $400 \mathrm{mg} \mathrm{m}^{-2}$ in metastatic breast cancer patients, yielded leucopenia grade $3-4$ in two out of $20(10 \%)$ patients and thrombocytopenia grade 3 in one out of $20(5 \%)$ patients as worst haematological toxicities. But, due to permanent myelosuppression, five cycles of carboplatin could be administered to only three patients (Kolarić and Vukas, 1991). Overall, the prolonged cytopenia concerning both platelets and neutrophils, which was 
observed in our study, can be explained on the basis of exposure to single agent carboplatin.

Conversely, these toxicities are at least not caused by indisulam single agent therapy. Thrombocytopenia usually occurred later than leucopenia between days 9 and 14 and was of short duration (median 3 days; range 1-6 days). Leucopenia typically occurred at day 8 (range days $7-12$ ) of the first cycle, and was associated with neutropenia at day 10 (range days 6-11), lasted for a median period of 8 days (range 7-9 days) and was fully reversible. Of the 21 cycles of indisulam given at the $700 \mathrm{mg} \mathrm{m}^{-2}$ dose level as $1 \mathrm{~h}$ infusion, every 3 weeks, to heavily pretreated patients, grade 3 or 4 neutropenia, thrombocytopenia or anaemia was reported in two cycles $(9.5 \%)$, three cycles $(14 \%)$ and one cycle $(4.7 \%)$, respectively (Raymond et al, 2002).

The exposure to carboplatin was higher than anticipated in all patients owing to overestimation of the carboplatin clearance by application of the Calvert formula (with GFR estimated by $\mathrm{CL}_{\mathrm{cr}}$ derived from Cockcroft-Gault). Consequently, higher doses than required to reach the predefined AUC values were administered. This has contributed to the high level of haematological toxicity that was observed in this study. In addition to the relatively high exposure to carboplatin, a pharmacodynamic interaction with indisulam may have caused excessive haematological toxicity in this study. Indisulam reduces the transcription of glutathione transcriptase and glutathione reductase resulting in a reduction of intracellular glutathione levels. This may not only enhance antitumour activity of carboplatin, but it may also increase haematological toxicity. This hypothesis is supported by the effect of L-carnitine, which protects against carboplatin-induced myelosuppression by increasing the intracellular glutathione content during treatment with carboplatin (Abd-Allah et al, 2005).

Obviously, it cannot be excluded, but is merely to be expected that the synergism determined for the combination of the two drugs in preclinical experiments is the reason for the observed

\section{REFERENCES}

Abd-Allah AR, Al-Majed AA, Al-Yahya AA, Fouda SI, Al-Shabana OA (2005) -carnitine halts apoptosis and myelosuppression induced by carboplatin in rat bone marrow cell cultures (BMC). Arch Toxicol 79: $406-413$

Beal SL, Boeckman AJ, Sheiner LB (1988) NONMEM User's Guides. San Francisco, CA: University of California at San Francisco

Belani CP, Aisner J, Hiponia D, Ramanathan R (1996) Paclitaxel and carboplatin in metastatic non-small cell lung cancer: preliminary results of a phase I study. Semin Oncol 23(Suppl 12): 19-21

Beumer JH, Rosing H, Hillebrand MJ, Nan-Offeringa LG, Foley K, Yule SM, Heck AJ, Schellens JH, Beijnen JH (2004) Quantitative determination of the novel anticancer drug E7070 (indisulam) and its metabolite (1, 4-benzene disulphonamide) in human plasma, urine and faeces by high-performance liquid chromatography coupled with electrospray ionization tandem mass spectrometry. Rapid Commun Mass Spectrom 18: $2839-2848$

Bunn Jr PA, Van Zandwijk N, Pastorino U, Aisner J, Alberto P, Arriagada R, Carney D, Cornis R, Dittrich C, Gatzemeier U, Ginsberg R, Greco FA, Hansen HH, Harper P, Henriksson R, Huber H, Klener P, LeChevalier T, Lewensohn R, Murray N, Niederle N, Postmus P, Rosell R, Scagliotti G, Sculier JP, Splinter T, Stahel R, Symann M, Thatcher N, Tonato M, Turrisi A (1994) First Euro-American Forum on lung cancer treatment of the European School of Oncology. Eur J Cancer 30A: $710-713$

Calvert AH, Harland SJ, Newell DR, Siddik ZH, Jones AC, McElwain TJ, Raju S, Wiltshaw E, Smith IE, Baker JM, Peckham MJ, Harrap KR (1982) Early clinical studies with cis-diammine-1, 1-cyclobutane dicarboxylate platinum II. Cancer Chemother Pharmacol 9: 140-147

Calvert AH, Newell DR, Gumbrell LA, O'Reilly S, Burnell M, Boxall FE, Siddik ZH, Judson IR, Gore ME, Wiltshaw E (1989) Carboplatin dosage: prospective evaluation of a simple formula based on renal function. J Clin Oncol 7: 1748-1756 prolonged cytopenia of both platelets and neutrophils as observed in our study.

The pharmacokinetic characteristics of indisulam were not significantly affected by carboplatin, which was demonstrated by the lack of bias in Figure 1. Carboplatin clearance was lower than previously reported values and consistently lower than predicted by the Calvert formula (Figure 2). It is unlikely that indisulam affects renal elimination of carboplatin, because only seven out of 391 patients that had previously been treated with indisulam had renal dysfunction. More probably, the low carboplatin clearance was related to overestimation of the GFR by two mechanisms. Serum creatinine is often assumed to be eliminated by passive renal elimination only. However, active tubular secretion accounts for about $20 \%$ of creatinine clearance. The tubular secretion may be counterbalanced by overestimation of the serum creatinine level as a result of the interference of non-creatinine chromogens with the alkaline picrate method of Jaffe (Diskin, 2006). Conversely, in our study, serum creatinine levels were measured by more accurate enzymatic methods. The consequent lack of a compensation for the tubular secretion of creatinine may have caused an overestimation of the GFR and consequently of the carboplatin clearance.

In conclusion, this study showed that the combination of indisulam with carboplatin was safe and a MTD for the phase II study was identified. The three-weekly treatment schedule was not feasible owing to thrombocytopenia and was therefore extended to a four-weekly regimen.

\section{ACKNOWLEDGEMENTS}

This research was partly performed within the frame of the CESAR Central European Society for Anticancer Drug Research - EWIV and supported by a grant from the Eisai network of companies.
Choy H, Shyr Y, Cmelak AJ, Mohr PJ, Johnson DH (2000) Patterns of practice survey for non-small cell lung carcinoma in the US. Cancer 88: $1336-1346$

Cockcroft DW, Gault MH (1976) Prediction of creatinine clearance from serum creatinine. Nephron 16: $31-41$

Diskin CJ (2006) More on case 7-2006. N Engl J Med 355: 1502-1503

Ekhart C, deJonge ME, Huitema ADR, Schellens JHM, Rodenhuis S, Beijnen JH (2006) Flat dosing of carboplatin is justified in adult patients with normal renal function. Clin Cancer Res 12: 6502-6508

Fukuoka K, Usuda J, Iwamoto $\mathrm{Y}$, Fukumoto $\mathrm{H}$, Nakamura $\mathrm{T}$, Yoneda T, Narita N, Saijo N, Nishio K (2001) Mechanisms of action of the novel sulfonamide anticancer agent E7070 on cell cycle progression in human non-small cell lung cancer cells. Invest New Drugs 19: $219-227$

Huitema AD, Mathôt RA, Tibben MM, Schellens JH, Rodenhuis S, Beijnen $\mathrm{JH}$ (2000) Validation of techniques for the prediction of carboplatin exposure: application of Bayesian methods. Clin Pharmacol Ther 67: $621-630$

Johnson DH, Paul DM, Hande KR, Shyr Y, Blanke C, Murphy P, Lewis M, De Vore III RF (1996) Paclitaxel plus carboplatin in advanced non-smallcell lung cancer: a phase II trial. J Clin Oncol 14: 2054-2060

Kolarić K, Vukas D (1991) Carboplatin activity in untreated metastatic breast cancer patients-results of a phase II study. Cancer Chemother Pharmacol 27: 409-412

Langer CJ, Leighton JC, Comis RL, O’Dwyer PJ, McAleer CA, Bonjo CA, Engstrom PF, Litwin S, Ozols RF (1995) Paclitaxel and carboplatin in combination in the treatment of advanced non-small-cell lung cancer; a phase II toxicity, response, and survival analysis. J Clin Oncol 13: $1860-1870$

Martin M, Diaz-Rubio E, Casado A, Santabárbara P, López Vega JM, Adrover E, Lenaz L (1992) Carboplatin: an active drug in metastatic breast cancer. J Clin Oncol 10: $433-437$ 
Muggia FM, Vafai D, Natale R, Israel V, Zaretsky S, McRae A, Rogers M, Jeffers S (1995) Paclitaxel 3-hour infusion given alone and combined with carboplatin: preliminary results of dose-escalation trials. Semin Oncol 22(Suppl 9): 63-66

O'Brien MER, Talbot DC, Smith IE (1993) Carboplatin in the treatment of advanced breast cancer: a phase II study using a pharmacokinetically guided dose schedule. J Clin Oncol 11: 2112-2117

Oda Y, Owa T, Sato T, Boucher B, Daniels S, Yamanaka H, Shinohara Y, Yokoi A, Kuromitsu J, Nagasu T (2003) Quantitative chemical proteomics for identifying candidate drug targets. Anal Chem 75: $2159-2165$

Owa T, Ozawa Y, Yokoi A, Nagasu T, Renshaw FG, Yule M (2004) Identification of response marker genes of the anti-tumour sulfonamide indisulam (E7070). Eur J Cancer Suppl 2: 128, abstract no. 427

Ozawa Y, Owa T, Yokoi A, Yoshimatsu K, Asada M (2004) The combination of indisulam (E7070) with cisplatin, oxaliplatin and 5-fluorouracil are synergistic in vitro and in vivo. Eur J Cancer Suppl 2: 126, abstract no. 420

Raymond E, ten Bokkel Huinink WW, Taieb J, Beijnen JH, Faivre S, Wanders J, Ravic M, Fumoleau P, Armand JP, Schellens JH (2002) Phase I and pharmacokinetic study of E7070, a novel chloroindolyl sulfonamide cell-cycle inhibitor, administered as a one-hour infusion every three weeks in patients with advanced cancer. J Clin Oncol 20: $3508-3521$

Schiller JH, Harrington D, Belani CP, Langer C, Sandler A, Krook J, Zhu J, Johnson DH, for the Eastern Cooperative Oncology Group (2002)
Comparison of four chemotherapy regimens for advanced non-small-cell lung cancer. $N$ Engl J Med 346: $92-98$

Shen M, Schilder RJ, Obasaju C, Gallo JM (2002) Population pharmacokinetic and limited sampling models for carboplatin administered in high-dose combination regimens with peripheral blood stem cell support. Cancer Chemother Pharmacol 50: 243-250

Talbot D, Norbury C, Slade M, von Pawel J, Bosquee L, Ellis PA, Gatzemeier U, Ravic M (2002) A phase II and pharmacodynamic study of E7070 in patients with non-small cell lung cancer (NSCLC) who have failed platinum-based chemotherapy. Proc Am Soc Clin Oncol 21: 327a, abstract no. 1306

van Kesteren $\mathrm{Ch}$, Mathôt RA, Raymond E, Armand JP, Dittrich $\mathrm{Ch}$, Dumez H, Roche H, Droz JP, Punt C, Ravic M, Wanders J, Beijnen JH, Fumoleau P, Schellens JH (2002) Population pharmacokinetics of the novel anticancer agent E7070 during four phase I studies: model building and validation. J Clin Oncol 20: 4065-4073

van Warmerdam LJC, van Tellingen O, Maes RAA, Beijnen JH (1995) Validated method for the determination of carboplatin in biological fluids by Zeeman atomic absorption spectrometry. Fresenius J Anal Chem 351: 777-781

Wiltshaw E, Smales E, Gallagher CJ, Staffurth J (1987) Carboplatin (paraplatin) in ovarian cancer. Anticancer Drug Res 9: 3-8

Zandvliet AS, Schellens JH, Copalu W, Beijnen JH, Huitema AD (2006) A semi-physiological population pharmacokinetic model describing the non-linear disposition of indisulam. J Pharmacokinet Pharmacodyn 33: $543-570$ 